\title{
Familial Hemophagocytic Lymphohistiocytosis Presenting as Hydrops Fetalis
}

\author{
Sota Iwatani, MD ${ }^{1}$ Kazuya Uemura, $\mathrm{MD}^{1} \quad$ Masami Mizobuchi, MD, $\mathrm{PhD}^{1}$ Seiji Yoshimoto, MD, $\mathrm{PhD}^{1}$ \\ Keiichiro Kawasaki, MD, $\mathrm{PhD}^{2}$ Yoshiyuki Kosaka, MD, PhD² Masayuki Hori, $\mathrm{MD}^{3}$ \\ Takahiro Yasumi, MD, $\mathrm{PhD}^{3}$ Hideto Nakao, MD, $\mathrm{PhD}^{1}$ \\ ${ }^{1}$ Department of Neonatology, Hyogo Prefectural Kobe Children's \\ Hospital, Hyogo, Japan \\ 2 Department of Hematology and Oncology, Hyogo Prefectural Kobe \\ Children's Hospital, Hyogo, Japan \\ ${ }^{3}$ Department of Pediatrics, Kyoto University Graduate School of \\ Medicine, Kyoto, Japan \\ Am J Perinatol Rep 2015;5:e22-e24. \\ Address for correspondence Sota Iwatani, MD, Department of \\ Pediatrics, Kobe University Graduate School of Medicine, 7-5-2, \\ Kusunoki-cho, Chuo-ku, Kobe, Hyogo 650-0017, Japan \\ (e-mail: sotaiwa@med.kobe-u.ac.jp).
}

\begin{abstract}
Keywords

- familial hemophagocytic lymphohistiocytosis

- hydrops fetalis

- hepatosplenomegaly

- cytopenia

- immunosuppressive chemotherapy

Background Familial hemophagocytic lymphohistiocytosis (FLH) is an autosomal recessive disorder of immune regulation that leads to a hyperinflammatory syndrome. Fetal onset FHL is extremely rare and is considered to be the most severe form of FHL. Case We report a preterm case of FHL that presented as hydrops fetalis. The infant was treated with a chemotherapy regimen based on the HLH-2004 protocol from the third day of life. However, he had persistent cytopenia and died on the 18th day of life due to bacteremia. The detection of defective perforin expression in the patient's natural killer cells and mutations in the PRF1 gene resulted in a molecular diagnosis of FHL.

Conclusion We suggest that early diagnosis and the development of an appropriate immunosuppressive strategy that can induce and maintain remission until hematopoietic stem cell transplantation can be performed are required to improve the outcomes of fetal onset FHL.
\end{abstract}

Hemophagocytic lymphohistiocytosis (HLH) is caused by the prolonged and excessive activation of T-cells and macrophages. ${ }^{1}$ HLH encompasses several entities; that is, primary familial HLH (FHL), which has an estimated incidence of 1 in 50,000 births, and a secondary form of HLH associated with infection, malignancies, and rheumatological disorders. ${ }^{2}$ FHL is a rare autosomal recessive disorder in which four different gene defects have been identified: PRF1 (FHL2), UNC13D (FHL3), STX11 (FHL4), and STXBP2 (FHL5). ${ }^{1,3}$

Most children with FHL are born healthy and become ill in the first 2 to 6 months of life. ${ }^{4}$ Neonatal presentation is rare, ${ }^{5}$ and the diagnosis of the condition is frequently delayed. In fact, it is often missed completely or only diagnosed at autopsy. ${ }^{6}$ In addition, fetal onset FHL is extremely rare and is considered to be the most severe form of FHL., ${ }^{4,6}$ Here, we report a preterm case of fetal onset FHL2.

received

October 9, 2014 accepted after revision

November 25, 2014

published online

March 4, 2015
$10.1055 / \mathrm{s}-0034-1544110$ ISSN 2157-6998.

\section{Case Report}

Our patient was a male newborn infant with a gestational age of $36^{5 / 7}$ weeks and a body weight of $2,665 \mathrm{~g}$. He was the third child of unrelated healthy parents and had healthy brothers. Maternal screening tests for toxoplasmosis, rubella, cytomegalovirus, human immunodeficiency virus, and human parvovirus produced negative results. The patient was delivered by emergency cesarean section because of fetal ascites and a nonreassuring fetal status. His Apgar scores were 4 and 7 at 1 and 5 minutes, respectively, and he was intubated and placed on mechanical ventilation due to respiratory distress. In addition, he had diffusely distributed small purple and red spots on his trunk and extremities (-Fig. 1). His liver and spleen had descended 2 and $1 \mathrm{~cm}$ below the right and left costal margins, respectively. A blood test produced the

Copyright $\odot 2015$ by Thieme Medical Publishers, Inc., 333 Seventh Avenue, New York, NY 10001, USA. Tel: +1(212) 584-4662.
License terms

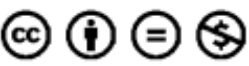




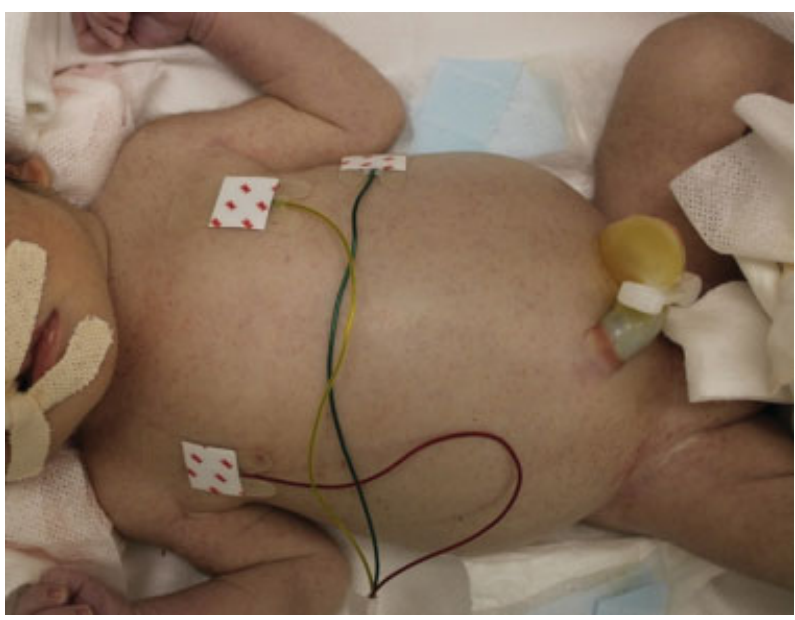

Fig. 1 At birth, diffusely distributed small purple and red spots were present on the infant's trunk and extremities.

following findings: hemoglobin, $10.1 \mathrm{~g} / \mathrm{dL}$; white blood cell count, $2.5 \times 10^{9} / \mathrm{L}$, including $6.0 \%$ immature neutrophils, $12.0 \%$ segmented neutrophils, $15.5 \%$ monocytes, $65.0 \%$ lymphocytes, and $0.5 \%$ atypical lymphocytes; platelet count, $14 \times 10^{9} / \mathrm{L}$; total protein, $4.2 \mathrm{~g} / \mathrm{dL}$; total bilirubin, $3.49 \mathrm{mg} /$ $\mathrm{dL}$; aspartate aminotransferase (AST), $144 \mathrm{IU} / \mathrm{L}$; alanine aminotransferase (ALT), $31 \mathrm{IU} / \mathrm{L}$; lactate dehydrogenase (LDH), $917 \mathrm{IU} / \mathrm{L}$; ferritin, 4,176 ng/mL; and C-reactive protein, 2.23 $\mathrm{mg} / \mathrm{mdL}$. An abdominal ultrasound examination detected hepatosplenomegaly and ascites. We diagnosed the patient with a congenital bacterial or viral infection, and he was treated with antibiotics, gamma globulins, and an exchange transfusion. However, we could not specify the cause of his infection, and his cytopenia did not improve despite repeated transfusions of platelets, red cells, and fresh frozen plasma.

The serum concentrations of cytokines were measured before the exchange transfusion. The patient's serum interleukin (IL)-6, IL-8, and tumor necrosis factor $\alpha$ levels were $133.0 \mathrm{pg} / \mathrm{mL}$ (normal: $<4 \mathrm{pg} / \mathrm{mL}$ ), $65.5 \mathrm{pg} / \mathrm{mL}$ (normal: $<2 \mathrm{pg} / \mathrm{mL}$ ), and $40.5 \mathrm{pg} / \mathrm{mL}$ (normal: $0.6-2.8 \mathrm{pg} / \mathrm{mL}$ ), respectively. Laboratory tests performed on blood samples obtained on the first day of life showed significantly elevated serum levels of AST (7,173 IU/L), ALT (1,233 IU/L), LDH (14,730 IU/L), ferritin $(115,360 \mathrm{ng} / \mathrm{mL})$, and soluble IL-2 receptor $(5,400 \mathrm{IU} /$ $\mathrm{mL}$, normal: $145-519 \mathrm{U} / \mathrm{mL}$ ). In addition, the patient's serum triglyceride and $\beta_{2}$-microglubulin levels were $107 \mathrm{mg} / \mathrm{dL}$ (normal: $40-150 \mathrm{mg} / \mathrm{dL}$ ) and $9.2 \mathrm{mg} / \mathrm{L}$ (normal: $0.68-1.65$ $\mathrm{mg} / \mathrm{L}$ ), respectively. The patient's natural killer (NK) cell function was markedly reduced (0\%, normal: $18-40 \%)$. On the third day, a bone marrow aspiration biopsy detected hemophagocytosis together with increased numbers of macrophages and histiocytes, which were consistent with HLH.

We treated the patient from the third day of life with a chemotherapy regimen based on the HLH-2004 protocol. $^{7}$ We intravenously administered dexamethasone $(0.5 \mathrm{mg} / \mathrm{kg} / \mathrm{d})$ and cyclosporine $\mathrm{A}(2 \mathrm{mg} / \mathrm{kg} / \mathrm{d})$, but the patient's condition deteriorated. In addition, etoposide was administered intravenously at a dose of $100 \mathrm{mg} / \mathrm{m}^{2}$ twice a week. Although the patient's edema improved slightly, leukopenia $\left(<0.5 \times 10^{9} / \mathrm{L}\right)$ and thrombocytopenia $\left(<50 \times 10^{9} / \mathrm{L}\right)$ persisted. On the 16 th day of life, the infant developed bacteremia because of Pseudomonas aeruginosa, and he died on the 18th day of life. Flow cytometric analysis revealed an absence of perforin expression in his NK cells (-Fig. 2), and postmortem DNA analysis identified mutations in the PRF1 gene (c.1A $>\mathrm{G}$ and c.1090_1091delCT).

\section{Discussion}

Neonatal HLH has been described in the previous studies of pediatric $\mathrm{HLH}^{5,8}$; however, the characteristics of neonatal HLH have not been well defined. The clinical findings of neonatal HLH are very similar to those of congenital infections. In a nationwide Japanese survey, Suzuki et al indicated that neonates with hepatomegaly, thrombocytopenia, and elevated LDH levels should be examined further for potential $\mathrm{HLH}^{6}$ Maruyama et al reviewed six case reports involving seven premature infants with congenital HLH. ${ }^{9}$ Four of the patients were diagnosed with FHL; however, a definitive diagnosis of FHL was not obtained in the other three cases. Ascites and hepatosplenomegaly were detected in almost all the cases, and hydrops fetalis was also seen in four cases. Our patient presented with hydrops fetalis, ascites, and hepatosplenomegaly. In addition, cytopenia, hyperferritinemia, and elevated LDH levels were facilitated the early diagnosis of neonatal HLH in this case.

Previous reports have shown that untreated FHL is uniformly fatal within 2 years of diagnosis. ${ }^{5}$ Isaacs reviewed the cases of 72 fetuses and neonates with HLH and found that they exhibited an overall survival rate of $26 \%{ }^{8}$ Among the latter patients, only 3 of the $34(9 \%)$ patients who were diagnosed with FHL had survived compared with 10 of the 17 (59\%) patients with infection-associated hemophagocytic syndrome. Immunosuppressive chemotherapy results in the control of FHL in some cases; however, remission is rarely sustained. Most patients suffer an early death unless they undergo hematopoietic stem cell transplantation (HSCT), which appears to be the only curative approach. ${ }^{8}$ Our patient died on the 18th day of life despite early diagnosis and immunosuppressive chemotherapy. Suzuki et al described 20 cases of
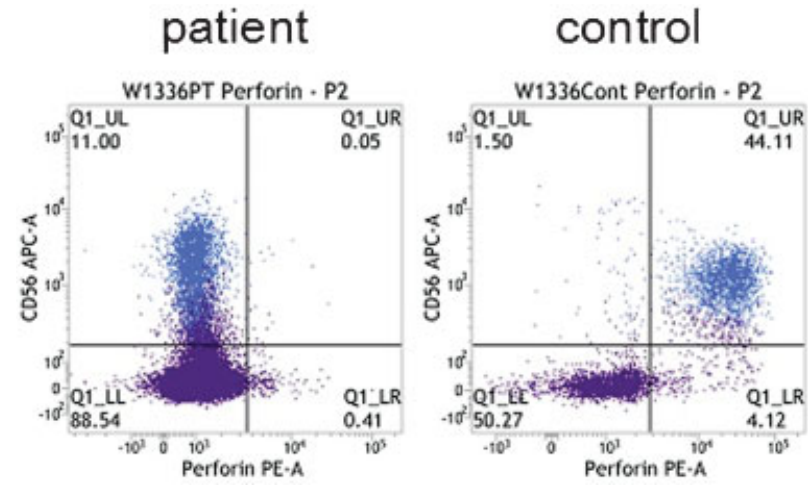

Fig. 2 Fluorescence-activated cytometric analysis of perforin expression in CD3-peripheral lymphocytes obtained from the patient and a healthy control. Perforin expression was markedly reduced in the patient's CD56+ cells. 
neonatal HLH that occurred in Japan during a 10 -year period. ${ }^{6}$ Of the three patients with genetically confirmed FHL, two died without receiving HSCT on the 29th and 114th day of life because of progression of the disease, respectively, whereas one patient who was treated with HSCT survived. Although the HLH-2004 protocol proved effective inducing remission in FHL, it may be insufficient for the treatment of neonatal onset FHL. Other less myelotoxic immunotherapies, such as antithymocyte globulin, could be combined with pre-HSCT therapy. A study involving a mouse model of FHL suggested that targeted immunotherapy might play a role in treating FHL, as improved recovery and survival were observed in mice treated with antiinterferon-gamma monoclonal antibodies. ${ }^{10}$ Recently, a humanized monoclonal anti-CD 52 antibody, CAMPATH-1H, has been used to treat refractory FHL. ${ }^{11}$ The deletion of T-cells and B-cells with CAMPATH-1H could be considered as an optional treatment for neonatal onset FHL. Also, mesenchymal stem cells, which are known to display multipotency and robust anti-inflammatory and regenerative properties, have been used to treat a range of immune-mediated conditions including graft versus host disease. ${ }^{12}$ We hope that the clinical application of these novel immunosuppressive strategies will help induce and maintain remission in FHL neonates until HSCT can be performed.

\section{Conflicts of Interest}

The authors have no conflicts of interest to declare.

\section{Acknowledgments}

We thank the patient's family for their kind cooperation and for giving the permission to publish photographs of the patient. We also thank Dr. Keiko Wada, Dr. Hitomi Sakai, and Dr. Aiko Kozaki for their help with the clinical management of our patient.

\section{References}

1 Janka GE. Familial and acquired hemophagocytic lymphohistiocytosis. Eur J Pediatr 2007;166(2):95-109

2 Janka G, Imashuku S, Elinder G, Schneider M, Henter JI. Infectionand malignancy-associated hemophagocytic syndromes. Secondary hemophagocytic lymphohistiocytosis. Hematol Oncol Clin North Am 1998;12(2):435-444

3 zur Stadt U, Rohr J, Seifert W, et al. Familial hemophagocytic lymphohistiocytosis type 5 (FHL-5) is caused by mutations in Munc18-2 and impaired binding to syntaxin 11. Am J Hum Genet 2009;85(4):482-492

4 Bechara E, Dijoud F, de Saint Basile G, Bertrand Y, Pondarré C. Hemophagocytic lymphohistiocytosis with Munc13-4 mutation: a cause of recurrent fatal hydrops fetalis. Pediatrics 2011;128(1): e251-e254

5 Aricò M, Janka G, Fischer A, et al; FHL Study Group of the Histiocyte Society. Hemophagocytic lymphohistiocytosis. Report of 122 children from the International Registry. Leukemia 1996;10(2): 197-203

6 Suzuki N, Morimoto A, Ohga S, Kudo K, Ishida Y, Ishii E; HLH/LCH Committee of the Japanese Society of Pediatric Hematology. Characteristics of hemophagocytic lymphohistiocytosis in neonates: a nationwide survey in Japan. J Pediatr 2009;155(2):235-8. e1

7 Henter JI, Horne A, Aricó M, et al. HLH-2004: Diagnostic and therapeutic guidelines for hemophagocytic lymphohistiocytosis. Pediatr Blood Cancer 2007;48(2):124-131

8 Isaacs H Jr. Fetal and neonatal histiocytoses. Pediatr Blood Cancer 2006;47(2):123-129

9 Maruyama A, Takahashi N, Gunji Y, et al. Congenital hemophagocytic lymphohistiocytosis in a preterm infant: cytokine profile and a review of the disease. J Pediatr Hematol Oncol 2011;33(5): e209-e212

10 Pachlopnik Schmid J, Ho CH, Chrétien F, et al. Neutralization of IFNgamma defeats haemophagocytosis in LCMV-infected perforin- and Rab27a-deficient mice. EMBO Mol Med 2009;1(2): 112-124

11 Marsh RA, Allen CE, McClain KL, et al. Salvage therapy of refractory hemophagocytic lymphohistiocytosis with alemtuzumab. Pediatr Blood Cancer 2013;60(1):101-109

12 Salem HK, Thiemermann C. Mesenchymal stromal cells: current understanding and clinical status. Stem Cells 2010;28(3):585-596 